\title{
A MULTIPARENTALIDADE E SEUS EFEITOS SEGUNDO TRÊS PRINCÍPIOS FUNDAMENTAIS DO DIREITO DE FAMÍLIA
}

\author{
Carlos Eduardo Pianovski Ruzyk ${ }^{1}$ \\ Ligia Ziggiotti de Oliveira ${ }^{2}$ \\ Jacqueline Lopes Pereira ${ }^{3}$
}

\section{Resumo}

O artigo analisa a multiparentalidade como a simultaneidade de relações de parentesco entre pelo menos dois pais ou mães e seus filhos, e é tema relevante para a compreensão contemporânea de família. O reconhecimento da multiparentalidade resulta da tratados princípios da pluralidade das entidades familiares, afetividade e melhor interesse da criança e do adolescente, estudados no primeiro tópico do trabalho. Em seguida, examinam-se decisões judiciais e os efeitos jurídicos decorrentes do reconhecimento desse vínculo. A multiparentalidade foi recentemente admitida pelo STF, emergindo dúvidas, porém, quanto aos limites e possibilidades de sua apreensão pelo Direito e de sua eficácia jurídica.

Palavras-chave: Multiparentalidade; Afetividade; efeitos jurídicos; Direito de Família.

\section{INTRODUÇÃO}

No âmbito da filiação, a vivência do afeto tem enriquecido o debate jurídico, dando voz a modelos familiares construídos no mundo dos fatos e há muito relegados à invisibilidade. Cabe ao Direito não apenas observar sua proliferação, mas dar-lhes vestes jurídicas, oferecendo a eficácia compatível com os valores constitucionais que informam a família.

Eis a resposta para o que se entende por multiparentalidade: cuida-se do exercício de vínculos de parentalidade repartido entre mais de dois indivíduos.

Duas questões preliminares, porém, acabam por se apresentar: (a) os baldrames relativos à apreensão

\footnotetext{
${ }^{1}$ Professor de Direito Civil da Universidade Federal do Paraná (UFPR) e da Pontifícia Universidade Católica do Paraná (PUC/PR). Doutor em Direito das Relações Sociais pelo Programa de Pós-Graduação da Universidade Federal do Paraná. Email: carlospianovski@hotmail.com

${ }^{2}$ Doutoranda em Direitos Humanos e Democracia pelo Programa de Pós-Graduação da Universidade Federal do Paraná. Pesquisadora visitante do Instituto Max-Planck. Professora de Direito Civil do Centro Universitário Autônomo do Brasil. E-mail: ziggiotti@gmail.com

${ }^{3}$ Mestranda em Relações Sociais, no Programa de Pós Graduação em Direito da Universidade Federal do Paraná. Especialista em Direito de Família e Sucessões pela ABDConst. E-mail: jacqueline.lopes10@gmail.com
} 
jurídica do parentesco admitem a multiplicidade de vínculos de maternidade e de paternidade? (b) em caso positivo, qual é a multiplicidade de vínculos juridicamente apreensível - apenas aquela fundada na socioafetividade, ou também se admitiria a simultaneidade entre o vínculo socioafetivo e o vínculo exclusivamente biológico, mesmo à margem do liame socioafetivo?

A essas duas essenciais questões prévias se soma uma terceira, que consiste em saber qual a eficácia jurídica dessa multiplicidade de vínculos, tanto no aspecto existencial quanto no aspecto patrimonial.

Com efeito, a concreta multiparentalidade parece se concretizar mais frequentemente na hipótese em que três pessoas desejam ser reconhecidas como pais e/ou mães, mas nada impede que se contemple um quadro ainda mais numeroso e complexo, justificando a nomenclatura, que se refere a múltiplos pais.

Esta transcendência dos modelos padronizados, que preveem uma ou duas figuras no exercício da parentalidade, reproduz-se no campo fático há muito, embora sua proteção jurídica tenha ganhado espaço recentemente. Com a percepção da criança como sujeito de direito e figura participativa no arranjo familiar, surge uma gama de deveres aos adultos, pois seus filhos, em situação de vulnerabilidade pelas limitações da idade, têm expostas suas garantias. Compartilhar, portanto, este papel entre várias pessoas é possível, e assim têm feito várias famílias.

Demandas judiciais de quem se encaixa neste perfil atípico perturbam o silêncio normativo e se impõem ao Poder Judiciário, que tem buscado a construção de respostas, como recentemente ocorreu no âmbito do Recurso Extraordinário 898.060/SC no Supremo Tribunal Federal.

Um olhar atento aos princípios atinentes ao Direito de Família informa com mais justiça os casos em análise ${ }^{4}$. Considerando a doutrina, pois, o trabalho propõe reflexão que admite a possibilidade de se dar azo à multiparentalidade, e problematiza as situações em que se pode, efetivamente, cogitar dessa multiplicidade de vínculos jurídicos. Assim se pretende oferecer reflexão sobre as duas primeiras questões posta acima, a respeito da possibilidade jurídica da multiparentalidade e da configuração do seu suficiente suporte fático. Para isso, toma como fio-condutor o exame de três princípios: a pluralidade familiar, a afetividade e o melhor interesse da criança e do adolescente.

O trabalho percorre o panorama da concepção eudemonista de família aliada ao exame de princípios constitucionais reitores da tutela jurídica da família, com enfoque deitado sobre a multiparentalidade. $\mathrm{Na}$ sequência, trazem-se à baila decisões judiciais recentes para explicitar o enfrentamento da matéria na prática e destacam-se possíveis efeitos jurídicos decorrentes do reconhecimento desta complexidade que, em harmonia com a concretude, passa a receber cada vez mais respaldo do Direito, especialmente em matéria de alimentos,

\footnotetext{
${ }^{4}$ Entre as obras relevantes a respeito do tema, cabe citar PEREIRA, Rodrigo da Cunha. Princípios fundamentais norteadores para o direito de família. Belo Horizonte: Del Rey, 2005.
} 
guarda, direito de convivência e registro civil, de modo a enfrentar a questão atinente também à expressão eficacial do fenômeno jurídico.

\section{A MULTIPARENTALIDADE NO DIREITO DE FAMÍLIA CONTEMPORÂNEO SOB TRES PRINCIPIOS FUNDAMENTAIS}

Ganha força nas luzes lançadas ao Direito de Família brasileiro contemporâneo o papel da felicidade. Contudo, a sua realização não pode ser tida como objetiva, pois que é possível vislumbrá-la a partir de numerosos aspectos, como o da concepção eudemonista, que entende a felicidade como a realização pessoal dos membros que fazem parte de certo núcleo familiar.

Por evidente, não se trata de compreender o Direito e o Estado como promotores de felicidade. Não cabe a terceiros a interferência autoritária no conteúdo das concepções individuais de bem no espaço reservado à coexistência na vida privada. A concepção eudemonista, assim, consiste em assegurar um espaço de proteção jurídica para que os indivíduos possam, livremente, construir sua felicidade coexistencial, a partir de suas próprias concepções de bem.

Nem sempre, porém, foi assim. Isso porque, no passado, a família era tomada como lócus de manutenção da estabilidade social, como ente transpessoal que tinha valor em si mesmo, e não como instrumento para a busca da felicidade de seus integrantes ${ }^{5}$. Tal moldagem fora transportada para a racionalidade do Código Civil de 1916, que consagrava um único modelo como formador de família. Daí que cada figura desta família necessariamente fundada no casamento - existia para cumprir um papel social que lhe era confiado ${ }^{6}$.

Segundo as reflexões de Gustavo Tepedino sobre esse modelo regulatório de Direito de Família, a primazia pela paz doméstica em detrimento da realização dos indivíduos fundamentava a produção legislativa anterior à Constituição de 1988, quando sua senda principiológica atingiu mais profundamente esse ramo do direito Civil (TEPEDINO, 2004, p. 397).

A valorização da subjetividade dos que compõem o núcleo familiar não deve ser lida como exacerbação do hedonismo dos envolvidos na relação. Não se pode olvidar que se trata mesmo de um conjunto de subjetividades no qual não se deve buscar submissão de outrem, importando-lhes sofrimento, para a satisfação do desejo de um único indivíduo. Nesse trilhar, valioso o ponto de vista de Nobert Elias, que entende que o "eu" do

\footnotetext{
${ }^{5}$ Nessa linha, cabe referir às pioneiras lições de FACHIN, Luiz Edson. Direito de família: elementos críticos à luz do novo código civil brasileiro. 2. ed. Rio de Janeiro: Renovar, 2003. e OLIVEIRA, Lamartine Correa de; MUNIZ, Francisco José Ferreira. Curso de direito de família. 4. ed. Curitiba: Juruá, 2003.

${ }^{6}$ Nessa linha, em análise a respeito daquele modelo pretérito, pode-se afirmar que "A família é regida, sob essa racionalidade, como ente dotado de relativa autonomia, todo orgânico cujo bom funcionamento implica uma divisão interna em papeis, com funções específicas que devem ser exercidas pelos componentes desse ente mais amplo, dotado de uma 'existência própria' abstrata".
} 
indivíduo existe a partir das interações construídas com os demais (ELIAS, 1994, p. 36), dentre as quais na sociedade ocidental, sobressaem as relações familiares. A liberdade dos indivíduos, pois, é sempre coexistencial.

Os princípios desenvolvidos no trabalho, bem como outros relativos à família, devem observância à dignidade da pessoa humana e à consideração do indivíduo imerso "em relação". Neste sentido é que a ética da alteridade se faz presente numa família que satisfaça a concepção eudemonista? ${ }^{7}$.

Por isso, o Direito não pode ignorar as inúmeras maneiras de constituição da pessoa como tal neste laço que parece especialmente significativo para a realização pessoal.

Trata-se de apreender os vínculos familiares na sua realidade, e não a partir de modelos preordenados.

A família se desdobra em interações que, além de construírem a subjetividade dos que a compõem, são nicho de desigualdades substanciais. Maria Celina Bodin de Moraes considera as relações familiares sob duas perspectivas: a de conjugalidade e a de parentalidade. A autora visualiza que, em que pese possa existir nas conjugalidades uma relação desigual derivada do gênero, seu enfoque tem como objeto a diferenciação de relações entre adultos e entre adulto e criança ou adolescente, em que é evidente a verticalidade de posições pela diferença etária (MORAES, 2013).

A realização pessoal de crianças e adolescentes que vivem em família multiparental evidencia a simultaneidade das relações familiares de parentalidade. Essas pressupõem que o polo mais vulnerável do vínculo são as crianças e os adolescentes com direitos resguardados pelo(s) adulto(s) que exerçam o poder-dever de cuidado ${ }^{8}$.

Os princípios fundamentais da pluralidade, da afetividade e do melhor interesse da criança e do adolescente ampliam a compreensão da multiparentalidade no cenário de eudemonismo e relações de parentalidade. Sob essa premissa, o estudo verticaliza os três princípios mencionados sob o recorte dessa forma de relação familiar.

\section{A multiparentalidade como realização do princípio da pluralidade familiar}

A percepção de que é possível ser família sem enfrentar percalço de subsunção a determinada forma legal ou socialmente imposta é legitimar que as pessoas possam satisfazer seu desejo de compor tal arranjo de maneira livre e plural.

(PIANOVSKI RUZYK, 2005, p. 20-21.)

${ }^{7}$ A este respeito, confira-se a reflexão de Luiz Edson Fachin e Carlos Eduardo Pianovski Ruzyk, que consideram a dignidade da pessoa humana como resultante da compreensão desta ética da alteridade (FACHIN; PIANOVSKI RUZYK, 2008).

${ }^{8}$ Não se ignora, com isso, a lúcida lição de Lamartine Correa de Oliveira e Francisco Muniz, que afirmam, com razão, ser o exercício do poder familiar também um direito subjetivo dos pais, vinculado ao livre desenvolvimento da personalidade (OLIVEIRA; MUNIZ, 2003). Trata-se, sim, de constatar a escolha preferencial entre os núcleos de interesses, que recai, por clara opção constitucional, em proveito da criança e do adolescente. 
É também apreender as realidades familiares constituídas à margem do exercício de liberdade, mas cuja proteção jurídica é, ela própria, instrumento para que os indivíduos possam exercer o livre desenvolvimento de suas personalidades.

Com a promulgação da Constituição da República em 1988, à ordem jurídica foi entregue complexidade de que não podem se furtar seus intérpretes. Acerca do tema por ora em análise, destaca-se o art. 226 do mesmo texto legal, com previsão expressa do matrimônio, da união estável e da família monoparental como possíveis arranjos familiares.

A compreensão mais elementar da norma aponta para a superação do vínculo matrimonial como exclusiva forma de família. Todavia, considerar esta primeira leitura deve ser um passo para transcendê-la, afinal, os modelos ali elencados não são os únicos captados pelo Direito. Neste sentido, valiosa é a lição de Paulo Luiz Netto Lôbo, que ensina ser o caput de referido dispositivo cláusula geral de inclusão (LÔBO, 2002).

Supera-se, a partir de tal entendimento, a pretensão de que o legislador esgote em frias linhas as maneiras de ser família. Portanto, mesmo que fora do convencional, o arranjo que se mostrar como família deve assim ser denominado, de acordo com Ana Carla Harmatiuk Matos, "porque a utilização desse signo linguístico comporta um contexto de valores, sentimentos e emoções que firmam referências presentes na realidade concreta, não mais devendo ser ocultados" (MATOS, 2011, p. 950).

A pluralidade consagrada pela Constituição de 1988 informa o Direito de Família contemporâneo de maneira intrínseca, e a ele se concede status de princípio. Assim, conforme Rodrigo da Cunha Pereira, "sua força deve pairar sobre toda a organização jurídica, inclusive preenchendo lacunas deixadas por outras normas", sob pena de não ser possível "a aplicação de um direito que esteja próximo do ideal de justiça”" (PEREIRA, 2005, p. 36). A principiologia constitucional, afinal, demanda aplicação também direta e imediata entre os particulares, pois reconhecida sua eficácia horizontal.

A indefinição apriorística do que seja família expande a força do princípio. Sobre a necessidade de superar a busca deste conceito determinado, pode-se constatar que "exime-se o direito da secular pretensão de definir família por meio de um modelo abstrato e excludente de arranjos sociais que a ele não se subsumem - e, por conseguinte, das pessoas que os compõem" (PIANOVSKI RUZYK, 2005, p. 36-37).

É possível aferir, em matéria de Direito de Família, uma distinção entre enfoques de caráter protetivo e de caráter regulatório (OLIVEIRA, 2016).

Por enfoque regulatório, deve-se entender aquele que condiciona o reconhecimento da família ao disposto a modelos preordenados em lei. Vale dizer: será família apenas aquilo que o Direito definir aprioristicamente como tal. A regulação está, pois, no plano da existência, e não, apenas, no plano da eficácia.

Por outro lado, há um enfoque bastante diverso, de caráter libertário-protetivo, que se abstém de definir 
um modelo preordenado de família para a o plano da existência. A regulação ocorre apenas na seara eficacial, apreendendo-se como realidade familiar aquilo que assim se configura no plano dos fatos, no plano concreto da coexistência.

Para essa concepção libertário-protetiva, não cabe ao direito definir o que é e o que não é família, pois esta antecede o direito. Cabe ao jurídico apreender as realidades familiares para oferecer a devida proteção aos indivíduos que as integram, como sujeitos livres e titulares de direitos fundamentais.

O enfoque libertário-protetivo abre leque para o exercício da liberdade da pessoa em relação familiar e para a proteção concreta da sua dignidade, pois apreende a materialidade da vivência desatrelada de um modelo subordinado a uma formalidade genésica.

Assume-se, neste estudo, uma leitura vinculada ao enfoque libertário-protetivo, por entender-se que a ordem constitucional não parte de modelos preordenados de relações familiares.

Ao contrário: sendo a família, como dispõe o artigo 226 da Constituição, base da sociedade, não se pode olvidar que se está a tratar da sociedade "livre, justa e solidária" a que se refere o artigo 30, como objetivo da República.

Se a sociedade a ser construída é livre, justa e solidária, não são admitidos juízos prévios de exclusão sobre as relações concretas que constituem sua base, sob pena de se solapar a liberdade e o respeito à alteridade que são essenciais à construção da sociedade pretendida pela ordem constitucional.

Assim, não é papel do legislador ordinário dizer qual critério seguir para que se constitua uma família. Cabe apreender o concreto para garantir efeitos jurídicos àquela realidade que, pela autoevidência, explicita se o observador está diante de um arranjo familiar ou não. É preciso atentar para não recair num dogmatismo classificatório - tão sintomático entre os civilistas ${ }^{9}$. Destarte, a percepção de que família é existencial e não categorial, simplesmente por sabermos que existe, constitui passo relevante para o amplo reconhecimento da pluralidade.

São muitos os desdobramentos provenientes de novas formas de ser família e o postulado que impera por esse viés é o de "ser família no dia-a-dia". À guisa de exemplo, citam-se algumas modalidades que fogem das descritas no texto constitucional, como o paralelismo de uniões, as famílias solidárias, as famílias anaparentais e as famílias recompostas. Nesta última, também conhecida como "família mosaico" ou "família reconstituída” parece incidir com mais frequência a multiparentalidade, embora concebível em família fundada também no poliamor.

Segundo Paulo Lôbo, embora seja possível uma tutela jurídica autônoma das relações, o vínculo entre

\footnotetext{
${ }^{9}$ A tendência é apontada pelo jurista Luiz Edson Fachin ao denunciar o caminho tradicional e acrítico tomado no ensino tradicional do Direito Civil: “(...) há um conjunto de conceitos que estão pré-colocados para a compreensão; estão pré-postos para a aferição da aptidão de manusear esses conceitos. A realidade é submetida aos conceitos, e não o contrário”. (FACHIN, 2012, p. 66).
} 
padrasto ou madrasta subsume à parentalidade, "permitindo-se àqueles contribuir para o exercício do poder familiar do cônjuge ou companheiro sobre o filho/enteado, uma vez que a direção da família é conjunta dos cônjuges ou companheiros, em face das crianças e adolescentes que a integram" (LÔBO, 2011, p. 97).

Trata-se, pois, de superação de modelo historicamente concebido de família de que constam as figuras paterna e materna, exercidas por um homem e por uma mulher que, casados, têm seus filhos, frutos desta relação matrimonial. Cuida-se, portanto, de um reflexo de nossa condição em que se imbricam laços biológicos, afetivos, registrais, jurídicos, temperando a complexidade por ora analisada.

Nessa multiplicidade de relações concretas que se inserem no âmbito da família como realidade estão os vínculos de parentalidade, que, destarte, não se subsumem a modelos prontos, como a lógica presuntiva em que se pautava a ratio do Código Civil de 1916, para o qual o parentesco se definia, em seu juízo de legitimidade, pela origem da prole, advinda do casamento. Tampouco se restringe à realidade biológica - que nem sempre é, concretamente, na seara das relações sociais, fonte de parentalidade.

Inscreve-se nessa multiplicidade concreta dos vínculos também a parentalidade socioafetiva, construída na vivência da paternidade e da maternidade. Essa multiplicidade pode ser, inclusive, marcada pela simultaneidade de vínculos, como se poderá aferir na sequência deste estudo.

\section{A multiparentalidade como realização do princípio da afetividade}

A realização pessoal de cada membro de uma família parece encontrar sua máxima expressão na livre construção da afetividade. Da apreensão da afetividade como princípio aplicável ao Direito de Família, no que toca a parentalidade, é possível citar, dentre a produção legislativa, a Lei da Guarda Compartilhada (Lei 13.058/2014), a Lei da Adoção (12.010/2009), a Lei da Alienação Parental (Lei 12.318/2010) e o projeto de Estatuto das Famílias que, ao associar expressamente o parentesco como resultante da consanguinidade, da socioafetividade ou da afinidade, supera a atual redação do Código Civil, limitado ao indicar a existência de parentes de outra origem para além da consanguínea em seu art. 1.593 (CALDERÓN, 2013, p. 256-264). Ademais, a Lei Clodovil (Lei 11.924/2009) inovou ao permitir que o enteado ou a enteada adote o sobrenome do padrasto ou da madrasta, em claro cotejo ao afeto que estes indivíduos cultivam um pelo outro.

As expressões infraconstitucionais de apreensão do parentesco acima citadas decorrem da própria abertura conceitual trazida pela Constituição a respeito das relações familiares, e recebem fundamento na compreensão da afetividade como valor jurídico que impregna também a dimensão principiológica do Direito de Família contemporâneo.

Tal princípio ganha realce quando analisada a multiparentalidade, pois que, por óbvio, pelo menos um dos laços de parentalidade se construirá exclusivamente em razão da existência do afeto, "um vínculo de filiação 
construído pelo livre desejo de atuar em interação entre pai, mãe e filho do coração, formando verdadeiros laços de afeto, nem sempre presentes na filiação biológica” (MADALENO, 2008, p. 372).

O reconhecimento da afetividade como relevante para a seara jurídica representa trajeto enfrentado pelo Direito brasileiro, destacado o protagonismo dos Tribunais em sua admissão como norteador de decisões que dizem respeito a uma série de temas relativos ao Direito de Família, dentre os quais se destaca a filiação, pois o acertamento de questões deste âmbito "perpassa pelo respeito à dignidade da pessoa humana e pelo reconhecimento da socioafetividade como valor jurídico" (STEIN, 2008, p. 558). Tal compreensão culminou com a possibilidade de reconhecimento da posse de estado de filho como informadora da filiação socioafetiva, integrada pelo nome, trato e fama, mas que não se reduz à rigidez desses conceitos ${ }^{10}$.

O Supremo Tribunal Federal considerou de repercussão geral a discussão apresentada no Recurso Extraordinário 898.060/SC em torno da prevalência da paternidade socioafetiva sobre a biológica. Em sessão de setembro de 2016, a Corte fixou a seguinte tese sobre o tema: "A paternidade socioafetiva, declarada ou não em registro público, não impede o reconhecimento do vínculo de filiação concomitante baseado na origem biológica, com os efeitos jurídicos próprios" (STF, 2016). Ao ver de Ricardo Calderón, a referida tese tem três principais consequências. A primeira é o reconhecimento da afetividade como princípio jurídico incidente sobre as relações familiares; a segunda é igualar hierarquicamente os vínculos socioafetivo e biológico; e a terceira é firmar a possibilidade jurídica da multiparentalidade (CALDERÓN, 2016).

A rigor, o que restou decidido no âmbito do STF permite afirmar que a realidade da socioafetividade como fonte de parentalidade foi reconhecida por aquele Tribunal, que admite, ainda, a conformação de situações de multiparentalidade.

O que se pode ponderar, sem embargo, é quando o vínculo biológico será, efetivamente, fonte de parentesco.

O parentesco é fenômeno social e relacional, que se constitui sob a marca da afetividade. Essa é a realidade que se apreende na abertura conceitual do sistema.

Nessa linha, nem sempre o vínculo biológico se revelará concretamente como parentesco - como ocorre, por exemplo, com as hipóteses de inseminação artificial heteróloga. Ali, a despeito do liame biológico com o doador ou a doadora do material genético, não há vínculo social de parentalidade, a ser apreendido pelo jurídico.

Impende, ainda, problematizar a admissão, pelo STF, de hipóteses em que a multiparentalidade passa a ser admitida à margem de qualquer vínculo socioafetivo com o genitor biológico, de modo concomitante com o vínculo já estabelecido pela posse de estado.

\footnotetext{
${ }^{10}$ A lição é de Luiz Edson Fachin: "não há, com efeito, definição segura da posse de estado nem enumeração exaustiva de tais elementos, e, ao certo, nem pode haver, pois parece ser da sua essência constituir uma noção flutuante, diante da heterogeneidade
} 
Se o direito apreende a realidade da vida e lhe dá vestes jurídicas, é preciso reconhecer que a multiparentalidade efetivamente relacional, pautada na relação socioafetiva, não é uma simples escolha individual, nem, tampouco, se trata de situação que permeia a maioria das relações parentais constituídas na sociedade.

Daí porque se pode questionar se, como derivação da decisão do STF, não se poderia chegar além da realidade que a decisão pretende apreender, criando artificiais hipóteses de multiparentalidade que, a rigor, se justificariam não pelo seu suporte fático, mas, apenas, pelos potenciais efeitos jurídicos que seu reconhecimento ensejaria (como os efeitos sucessórios) ${ }^{11}$. Cabe, portanto, na aplicação do enunciado jurisprudencial, cuidado por parte do intérprete para evitar uma excessiva colonização do mundo da vida pelo Direito.

Na mesma linha, a correta aplicação do princípio da afetividade não permite que se confunda a socioafetividade, inclusive para fins de multiparentalidade, com a relação jurídica de afinidade entre padrastos/madrastas e enteados/enteadas. Tais relações podem vir a constituir paternidade/maternidade socioafetivas, como será demonstrado mais adiante, mas tal configuração não pode ser assumida como regra para a universalidade dos casos concretos. Tem, aqui, a tópica, especial papel.

O vínculo parental assim reconhecido, todavia, vai além do tratamento afetuoso e do cuidado, que se evidenciam também nas relações de afinidade, daí porque a necessária cautela na apreensão da presença ou não da tractatio e da reputatio típicas da parentalidade socioafetiva, ou seja, tratar-se e ser conhecido socialmente como filho.

O reconhecimento do vínculo parental socioafetivo não é um juízo de mera similitude: a socioafetividade não, simplesmente, se assemelha ao parentesco, mas é, na verdade, dele constitutiva. Não se trata de ser tratado e reconhecido "como se filho fosse", mas de ser, efetivamente, filho, na conformação de sua autoconstituição e na expressão fática dos vínculos coexistenciais.

É por isso que a posse de estado deixa de ser apenas prova subsidiária do parentesco, para se tornar dele constitutiva.

Se é certo que a complexidade da vida nem sempre permite a clara aferição dessa paternidade/maternidade construída no afeto, isso não deve servir de óbice nem ao reconhecimento das relações em que claramente tais vínculos se estabelecem nem, tampouco, à necessária distinção entre realidades familiares distintas na sua configuração e na sua eficácia jurídica.

Realizadas as distinções necessárias, cabe reconhecer que a multiparentalidade evita que o Direito, de

\footnotetext{
de fatos e circunstâncias que a cercam" (FACHIN, 1992, p. 161).

${ }^{11}$ Nessa linha, a solução mais adequada parece ser a cautelosa tese sustentada no voto vencido do Ministro Luiz Edson Fachin, ao não admitir a multiparentalidade pautada apenas no vínculo biológico quando já há parentesco socioafetivo com outrem. A tese do voto vencido tem também o mérito de assegurar a igualdade entre o vínculo parental definido por adoção e aquele constituído pela socioafetividade (STF, 2016).
} 
modo artificial, afronte a realidade da vida e imponha, entre dois vínculos socioafetivos, a escolha sobre de qual deles o filho seria privado. Havendo dois ou mais vínculos efetivos, pautado na afetividade socialmente apreendida como paternidade ou maternidade, todos esses liames serão juridicamente reconhecidos.

Atualmente, conforme se averiguou, se é possível atribuir função à família, a temos como a construção de espaço de afeto para possibilitar a cada membro a felicidade nesta convivência, evidenciando no cotidiano a concepção eudemonista contemporânea de família. Por esta razão é que reconhecer a multiparentalidade como saída possível em situações como as examinadas no presente estudo significa aplicar de maneira mais satisfatória o princípio da afetividade em Direito de Família.

\section{A multiparentalidade como realização do princípio do melhor interesse da criança e do adolescente}

O princípio do melhor interesse criança e do adolescente recebe amplo respaldo do ordenamento que, desde a Constituição à legislação infraconstitucional, com o Estatuto da Criança e do Adolescente, principalmente, busca efetivar seu reconhecimento como sujeito de direito, o que "significa, para a população infanto-juvenil, deixar de ser tratada como objeto passivo, passando a ser, como os adultos, titular de direitos juridicamente protegidos" (PEREIRA, 1999, p. 15).

Tal princípio é multifacetário: tem repercussões nas mais diversas áreas do Direito, como no âmbito penal, internacional ou civil. Entre nós, cabe destacar sua incidência nas relações familiares, especialmente no tocante à multiparentalidade, para que seja possível afirmar ser o reconhecimento deste arranjo familiar capaz de concretizar o princípio em análise.

O entendimento da parentalidade ultrapassa o que sugere o senso comum. Se a realidade relacional em que está o jovem inserido a ele vincula como pai e mãe sujeitos para além dos estabelecidos a priori pelo liame biológico ou pela expressão registral, melhor reconhecer aqueles em todos os âmbitos para garantir direitos e estabelecer deveres - com os cuidados para evitar, como exposto, a colonização do mundo da vida pelo Direito, chancelando como paternidade vínculos que socialmente não são assim compreendidos sequer pelos seus próprios integrantes.

Dentre as garantias, destaca-se a convivência, construtora do afeto e, portanto, com potencial de realizar os membros de determinada família, em harmonia com a concepção eudemonista. Em outras palavras, tal reconhecimento garante o cuidado cotidiano e comprometido pelos adultos na relação de parentalidade (MORAES, 2013).

É desafiadora a apreciação séria do melhor interesse da criança e do adolescente no caso concreto, porque uma situação com potencial afetivo para realizar plenamente o indivíduo em desenvolvimento, por vezes, 
é sufocada por parte dos operadores do Direito, em nome de uma leitura regulatória (no específico sentido antes explicitado) que não se coaduna com uma ordem constitucional que oferece à família a condição de base da sociedade livre, justa e solidária.

Explica-se: quando apresentada uma nova realidade em Direito de Família pautada no plural, não faltam argumentos que acusem a mudança como destruidora da família, e se tal entidade familiar envolve crianças, o argumento endurece e muitas vezes o preconceito é disfarçado em um discurso que se declara como atento ao melhor interesse do menor. Trata-se, contudo, de fala que se pauta em um conceito naturalizado e não histórico de família. A família atual, que passa longe do modelo unívoco e rígido antes prevalente, não tem fôrmas e a realização de uma criança independe delas.

Faz sentido, portanto, fortalecer o melhor interesse da criança e do adolescente para que sirva inclusive como parâmetro com fins de legitimar famílias diversas daquela codificada no início do século XX, para dar espaço a famílias conformadas pela sistemática constitucional contemporânea, ou seja, para dar espaço à pluralidade.

\section{A MULTIPARENTALIDADE EM JUIZO}

A dicotomia entre teoria e prática, comumente sustentada, sugere falácia. Ambas se complementam, e é impossível que se ignorem reciprocamente. $\mathrm{O}$ aporte teórico locomove a prática, ao passo que esta experimenta a teoria, reconstruindo-a constantemente. Com tal percepção em voga e como passo importante para examinar os efeitos do reconhecimento da multiparentalidade, citam-se casos concretos levados à apreciação judicial.

Os casos reconhecem a possibilidade jurídica da pluralidade de vínculos parentais e situam três hipóteses diferentes de concretização: a primeira veicula a existência de pai biológico e pai registral e com ambos a criança ou adolescente constrói o vínculo de socioafetividade; a segunda hipótese está no eixo de famílias recompostas, quando a criança ou adolescente desenvolve vínculo de socioafetividade com o padrasto ou madrasta; por fim, a terceira complexifica a multiparentalidade ao aliá-la ao planejamento familiar de casais homoafetivos, cujos filhos poderão ter vínculo socioafetivo também com o genitor ou genitora biológico, a depender do planejamento familiar erigido. Reitera-se que embora seja possível teorizar a multiparentalidade em famílias poliafetivas, o presente estudo não localizou casos judicializados com esse teor.

O primeiro caso que desponta a multiparentalidade em juízo se tornou paradigma para outros que o seguiram e, por ser uma das primeiras decisões que tratou expressamente da simultaneidade de vínculo socioafetivo da criança com pai biológico e pai registral, deve ser tratado com especial atenção. Do Estado de Rondônia, constou o caso em que se objetivava, por motivação da genitora, declarar a falsidade ideológica do reconhecimento de paternidade de um dos requeridos para que se declarasse pai o outro. Ocorre que aquele 
exerceu plenamente o papel paterno assumido, tendo criado com a criança, então com 11 anos, o vínculo socioafetivo, ao passo que este, pai biológico desconhecia sua existência. Ao primeiro contato com ela, ainda na audiência de coleta para o exame de DNA, emocionou-se e de pronto a levou para sua cidade de origem, onde seus familiares a acolheram carinhosamente.

Ouvida a criança, o juízo, em primeiro grau, descreveu que não pretendia abrir mão de qualquer dos vínculos. Conforme informaram os assistentes sociais e os psicólogos, ela esclareceu que "sua família é a do requerido M., mas que com a aproximação do requerido E. também terá outra família para lhe acrescentar, demonstrando empolgação com a possibilidade" (TJRO, 2016).

Diante da complexidade do caso, a julgadora proferiu sentença para acrescentar no assento de nascimento da autora o nome do genitor biológico, sem a exclusão daquele que havia a adotado à brasileira. Além disso, recebeu a autora o sobrenome do primeiro, mantendo também o de sua mãe e o do segundo, bem como passou a receber alimentos do pai biológico, a quem se garantiu o direito de convivência. Os fundamentos da decisão consideravam que a criança reconhecia como pai quem a criou, mas já construía evidentes laços de afeto com o outro pai que tanto a queria bem. Corretamente, ofereceu-se chancela jurídica ao amor.

Seguindo com exemplos capazes de demonstrar a relevância prática do tema, o estudo vislumbra a hipótese de multiparentalidade decorrente de famílias recompostas. Ana Carla Matos ressalta que a força normativa dos fatos envolvidos na família recomposta decorre da ruptura da estrutura familiar clássica e torna plástico os conceitos de família e de parentesco (MATOS, 2013, p. 321-322).

Menciona-se a decisão prolatada em primeiro grau na cidade de Cascavel, em que a afetividade de um adolescente voltava-se ao pai biológico e ao socioafetivo. Com o divórcio, cada qual dos genitores reestabeleceu vínculos familiares. O padrasto, inicialmente, requereu a adoção, com a qual o pai biológico concordava. Posteriormente, emendou a inicial com fins de que mantivessem o registro deste, bem como seu sobrenome, mas com sua inclusão também como pai, já que mantém vínculo socioafetivo com o adolescente desde que tinha tenra idade, embora o genitor jamais tenha deixado de visitar seu filho periodicamente.

O juiz de direito narrou o incômodo de todos os envolvidos enquanto achavam que o reconhecimento de um vínculo paterno excluiria automaticamente o outro, no caso, do pai biológico. Informados da possibilidade de multiparentalidade, considerou o magistrado "indescritível o momento de alívio, de felicidade, tanto do adotando, como do genitor, da genitora e do próprio requerente". O juiz pontuou que a lacuna em lei da situação exposta nos autos não exclui sua importância jurídica, de modo que os princípios referentes ao Direito de Família lhe oferecem proteção (TJPR, 2013). Neste sentido, decidiu pela inclusão do pai socioafetivo no registro civil, ao lado, portanto, dos pais biológicos.

Num outro caso, noticiou-se o registro de criança em nome dos pais biológicos e da madrasta em Recife 
(BOTTINI FILHO, 2013). De acordo com a reportagem, a guarda será compartilhada pelo trio, já que, embora tenha sido o infante criado pelos pais socioafetivos em razão da falta de condições financeiras da genitora, esta sempre se fez presente na vida do filho, caracterizando assim o que se denominou "filiação poliafetiva".

Ao início de 2015, a história de uma família recomposta repercutiu na sociedade quando o juízo da comarca de Votorantim autorizou a adoção unilateral de uma criança por seu padrasto e determinou a exclusão do nome de seu pai falecido e dos avós paternos do registro de nascimento. A mãe dificultava o contato da criança com o avô, que ainda viu esvanecer o vínculo registral com a neta $(G 1,2015)$.

Outro seria o desfecho se o magistrado reconhecesse a multiparentalidade, tal como ocorreu em caso concreto da comarca de Itu. O TJSP deu provimento ao pedido de inclusão do nome da mãe socioafetiva ao registro de nascimento do filho, sem, com isso, excluir o nome da mãe biológica, falecida em decorrência do parto apenas três dias depois do nascimento (TJSP, 2012). Casou-se o viúvo outra vez, quando o filho tinha dois anos, e desde então conviveram, tendo sua esposa assumido a relação de parentalidade. Ao invés de adotá-lo, a mãe socioafetiva e o filho preferiram prestar respeito àquela que, vitimada tragicamente, não merecia ter seu nome esquecido sequer no registro de nascimento da criança.

Como se observa, em todos esses exemplos a realidade do vínculo socioafetivo transcendeu o liame jurídico de afinidade, convertendo-se em vera e propria paternidade/maternidade.

O terceiro eixo de hipótese de multiparentalidade apresenta casos relacionados a outras questóes caras ao Direito de Família contemporâneo, como a reprodução humana assistida no auxílio do plano parental e parentalidade de casais homoafetivos. Em 2014, o Tribunal de Justiça do Rio de Janeiro julgou Agravo de Instrumento em Ação de Guarda Compartilhada ajuizada pelo pai biológico de uma criança concebida por inseminação artificial (TJRJ, 2014). A reprodução humana assistida foi fruto do planejamento familiar de duas mulheres que mantinham união estável entre si desde 2008. Um amigo das companheiras se propôs a doar o material genético para concretizar o plano e, quando a criança completou 2 anos, pleiteou a guarda compartilhada. A mãe biológica e registral pediu a inclusão de sua companheira no polo passivo da demanda, sob o argumento da existência de vínculo de maternidade socioafetiva. Porém, o juízo de primeiro grau indeferiu o pedido, o que justificou a interposição do Agravo de Instrumento.

Entendeu-se que a condição de mãe socioafetiva deveria ser tutelada, já que a gestação foi fruto do planejamento familiar das companheiras. O recurso foi provido e o voto da desembargadora relatora ressaltou inexistir hierarquia entre os vínculos socioafetivo e biológico, tanto da companheira, quanto do pai biológico que tanto queria construir vínculo socioafetivo com a criança, devendo a sua simultaneidade ser tutelada com vistas à proteção do melhor interesse desta.

A decisão reconheceu a existência fática da multiparentalidade por vínculo socioafetivo da criança com 
aquela que exerceu papel parental de cuidado e que, inclusive, foi quem participou do planejamento familiar do casal para a concepção da criança. O principal efeito jurídico constatado é o direito de convivência da criança com os três adultos que compõem a parentalidade e a igual importância de sua participação na tomada de decisões sobre a vida do menor. Note-se que o que vem à tona como critério determinante da multiparentalidade não é o liame biológico por si só, mas, sim, o vínculo relacional de socioafetividade.

Por fim, narra-se o caso da "Ação de divórcio consensual cumulada com Declaratória de Multiparentalidade" julgada pela 3a Vara de Família da comarca de Niterói-RJ em junho de 2016. A decisão homologou acordo em que três pessoas exerciam a parentalidade sobre uma criança: duas mulheres casadas entre si e um homem. Os três compartilhavam deveres e responsabilidades sobre o menino, que reconhece o vínculo de socioafetividade com os adultos. O plano parental foi convencionado de forma amigável e consolidou o regime de guarda compartilhada entre as duas mães e o pai da criança (TJRJ, 2016).

\section{REFLEXÕES SOBRE OS EFEITOS JURÍDICOS DA MULTIPARENTALIDADE}

Diante do reconhecimento da multiparentalidade, o presente estudo passa a se ater a alguns de seus efeitos jurídicos. Para tanto, faz-se uma ressalva: é inegável o movimento de repersonalização do Direito Civil como consequência da constitucionalização desta disciplina. A partir de tal percepção, os princípios relativos à proteção da pessoa tomam frente em relação aos que se referem ao patrimônio - que não deixam, todavia, de ocupar lugar relevante dentro do Direito Civil. Em outras palavras, é possível afirmar que, sob a perspectiva metodológica, o viés existencial se sobrepõe prima facie ao patrimonial segundo a sistemática contemporânea do ordenamento jurídico brasileiro.

Assim, não é o interesse patrimonial que justifica a proteção jurídica dos indivíduos em dada relação familiar. Esta se fundamenta no valor da dignidade da pessoa humana. Do reconhecimento de relações jurídicas e de direitos subjetivos, pode emergir a eficácia patrimonial, não podendo ser esta, sem embargo, o fundamento a justificar a apreensão jurídica e a atribuição de efeitos a dada relação social ${ }^{12}$.

Destarte, com a conformação do arranjo familiar, deduzem-se direitos de ordem existencial e material. Quanto àqueles, sustenta-se a possibilidade de adoção do sobrenome do pai, incluído em registro civil, conforme queiram as partes, bem como de decidir acerca da guarda e do regime de convivência, nos casos nos quais pais e

\footnotetext{
${ }^{12}$ Um indicativo concreto dessa prevalência prima facie, e do relevo oferecido à dimensão existencial, ainda que em situação diversa do parentesco socioafetivo propriamente dito, é a possibilidade aberta pela "Lei Clodovil" (Lei 11.924/2009) de o enteado ou enteada adotar o sobrenome do padrasto ou madrasta, sem que necessariamente haja efeitos patrimoniais. Por evidente, a ausência de tais efeitos somente se justifica desde que o vínculo socioafetivo formado não se qualifique como efetiva paternidade ou maternidade, hipótese em que, por incidência do princípio da igualdade da filiação, todos os direitos, sejam patrimoniais ou existenciais, serão plenamente reconhecidos.
} 
filhos não residem sob o mesmo teto, sempre em vista de resguardar o melhor interesse da criança. Assegurada, portanto, a importância deste perfil existencial, parece descabido conceber que consequências desta ordem sejam descartadas pelo apreciador do caso.

Quanto aos direitos de ordem material, contudo, salienta-se o seguinte: a obrigação alimentar decorrente da parentalidade é resultante da assistência material que devem a seus filhos, de modo que daí se abre a hipótese de pagamento de prestação alimentar por algum dos pais ${ }^{13}$.

Nos casos concretos descritos no item anterior, notou-se que a guarda na modalidade compartilhada e o direito de convivência dos pais ou mães são combustíveis para a manutenção e fortalecimento do vínculo socioafetivo. O caso noticiado com origem na cidade de Recifeé exemplo de efeito jurídico que resguarda a igualdade dos vínculos de parentalidade construídos com uma só criança e consequentemente atende o princípio do melhor interesse, já que se trata de um poder-dever que exige a responsabilidade e cuidado dos múltiplos pais com o filho (a).

Além de alimentos e guarda, o registro civil da multiparentalidade foi transversal aos casos apresentados, muito embora haja decisões judiciais que entendam por sua impossibilidade jurídica. Em obra que examina minuciosamente os efeitos da multiparentalidade, Christiano Cassettari indica ser de suma importância que a multiparentalidade constituída pela filiação biológica e socioafetiva seja averbada em registro civil para garantia da publicidade e segurança da produção de efeitos jurídicos (CASSETARI, 2014, p.178), o que também representa o resguardo do melhor interesse da criança.

O autor ainda elenca como efeitos jurídicos do reconhecimento do vínculo multiparental a responsabilidade dos pais ou mães em igual proporção perante a criança ou adolescente. Isso quer dizer que a eles caberá o papel de curadoria em caso de ausência do filho que não possua cônjuge, o papel de representante legal do(a) filho (a) até atingir dezesseis anos e de assistente enquanto for relativamente incapaz. Ainda, Cassettari aponta os efeitos referentes à emancipação voluntária e habilitação em casamento quando em idade núbil, autorizações que deverão ser feitas em conjunto para que sejam viabilizadas (CASSETARI, 2014).

Sobre os direitos sucessórios, tem-se nestes casos o reconhecimento de relações de parentesco, de modo que também se apresentam como efeitos do reconhecimento da multiparentalidade, na seara da sucessão legítima.

Por fim, conforme se expôs, a multiparentalidade trata-se de realidade familiar diversa da convencional. Merecem seus membros, segundo a melhor leitura constitucional, igual respeito sem que lhe sejam suprimidas

\footnotetext{
${ }^{13}$ Neste sentido, seguimos Luiz Edson Fachin e Ana Carla Harmatiuk Matos que do tema trataram ao enfrentar a questão da filiação socioafetiva: "(...) esse importante dado da vida social deve transpor-se para o direito, de modo que se sustente a possibilidade de "dois pais" ou "duas mães" estarem obrigados a alimentos frente a uma mesma criança." (FACHIN; MATOS, 2009, P.275).
} 
garantias, sob pena de violação à isonomia, seja entre as entidades familiares, seja entre os filhos.

É incipiente a lembrança de que a complexidade não pode ser motivo para afastar o desenvolvimento da matéria, mas sim incentivá-lo. Assim, o contemporâneo e gradativo reconhecimento pela jurisprudência de múltiplos pais numa relação traz desafios quanto a concretização de seus efeitos merece atenção comprometida dos juristas.

\section{CONCLUSÃO}

Com diversas nuances se pinta o quadro do desenvolvimento atual do Direito de Família. Dentre as diversas cores que têm tornado mais rico tal estudo, a leitura de casos pelas lentes constitucionais se responsabiliza por avanços notórios para a realização do princípio maior e que melhor harmoniza todos os outros, inclusive os que vieram a se apresentar neste trabalho: a dignidade da pessoa humana.

Tomada entidade familiar como capaz de concretizar a felicidade de cada um dos indivíduos que nela convivem, dota-se de tal potência a multiparentalidade, pois, longe de se adequar aos padrões tradicionais de família, outrora defendidos mesmo em lei como estáticos, conforta-se tal arranjo no reconhecimento da pluralidade. Sobre o melhor interesse da criança e do adolescente, concluiu-se que não se incluir em referidos padrões de família não significa, por si só, prejuízo para o filho destes múltiplos pais ou mães em questão. Pelo contrário: privá-lo de uma condição como esta pode significar exatamente o avesso da realização de seu melhor interesse, cujo escopo é garantir um seio familiar construído no amor, no cuidado, no exercício da paternidade em seu sentido mais puro. Parece, afinal, encontrar, em termos de filiação, a afetividade a verdadeira força de que atualmente goza na ideia de que a parentalidade é dado construído, e não mera consequência, para duas pessoas, de sua transmissão genética ${ }^{14}$.

Além disso, o reconhecimento jurídico da complexidade em comento é igualmente relevante para os envolvidos numa relação familiar. A ninguém cabe proferir o roteiro de como ser família, mas reconhecer pelo Direito tal condição é movimento de inclusão realizador para os membros. Ademais, traz-se, com isso, a segurança de que os efeitos jurídicos derivados de tal reconhecimento valerão. Dentre eles, destaca-se o uso do sobrenome de quem foi reconhecido como pai; o estabelecimento da guarda da criança; a convivência garantida pelas visitas frequentes. Quanto ao pagamento de alimentos, tem-se sua fixação como efeito patrimonial possível, mas sujeita ao crivo do binômio da necessidade do alimentado e da possibilidade do alimentando, para que não haja enriquecimento ilícito. Por fim, os efeitos sucessórios não se diferem entre os filhos, independentemente de sua origem, de modo que a multiparentalidade os garante aos que se reconhecem como pais e filhos desta peculiar

\footnotetext{
${ }^{14}$ Tal dado construído revela a verdade socioafetiva de que trata Luiz Edson Fachin (FACHIN, 1992).
} 
relação que, embora alheia à legislação e mesmo estranha ao senso comum, é frequentemente experimentada na convivência das famílias.

Por tudo isso, um espaço que apreende a pluralidade, a afetividade e o melhor interesse da criança e do adolescente como princípios fundamentais para o reconhecimento da multiparentalidade parece plenamente comprometido com a aferição da realização dos indivíduos que convivem neste arranjo familiar, aproximando-os ainda mais de um ideal de felicidade.

\title{
MULTIPARENTING AND ITS EFFECTS ACCORDING TO THREE FUNDAMENTAL PRINCIPLES OF FAMILY LAW
}

\begin{abstract}
The paper analyzes "multiparenting" as simultaneity of parenting relations among at least more than two parents and their children, and it is a relevant topic to understand contemporary family. The legal recognition of "Multiparenting" is a result of the application of plurality of families, affectivity and the best interest of the child principles, which are object of the paper's first section. Thereafter, the study analyses judicial decisions and Legal effects arising from this relationship. "Multiparenting" has been recently recognized by Brazilian's Supreme Court (STF), however, there are emerging doubts about its limits and possibilities of aprehension by Law, as well as its Legal effectiveness.
\end{abstract}

Keywords: Multiparenting; Afectivity; Legal effects; Family Law.

\section{REFERENCIAS}

BOTTINI FILHO, Luciano. Juiz de Recife registra criança em nome de pai, mãe e madrasta. Publicado em 25 de fevereiro de 2013. Disponível em: <http://veja.abril.com.br/noticia/brasil/juiz-de-recife-registra-crianca-emnome-de-pai-mae-e-madrasta $>$. Acesso em 16/11/2016.

CALDERÓN, Ricardo Lucas. Princípio da afetividade no Direito de Família. Rio de Janeiro: Renovar, 2013.

Reflexos da decisão do STF que acolheu a socioafetividade e a multiparentalidade. Disponível em: $<$ http://www.conjur.com.br/2016-set-25/processo-familiar-reflexos-decisao-stf-acolher-socioafetividademultiparentalidade $>$. Acesso em 09/11/2016.

CASSETTARI, Christiano. Multiparentalidade e parentalidade socioafetiva: efeitos jurídicos. São Paulo: Atlas, 2014.

ELIAS, Norbert. A sociedade dos indivíduos. Rio de Janeiro: Zahar, 1994.

FACHIN, Luiz Edson. Estabelecimento da filiação e paternidade presumida. Porto Alegre: Fabris, 1992.

Direito de família: elementos críticos à luz do novo código civil brasileiro. 2. ed. Rio de Janeiro: Renovar, 
2003.

Renovar, 2012.

Teoria crítica do direito civil: à luz do novo Código Civil Brasileiro. 3a Ed., rev. e atual. Rio de Janeiro:

FACHIN, Luiz Edson; MATOS, Ana Carla Harmatiuk Matos. Subsídios solidários: filiação socioafetiva e alimentos. In: Apontamentos críticos para o direito civil brasileiro contemporâneo. Coord.: Eroulths Cortiano Junior; Jussara Maria Leal de Meirelles; Luiz Edson Fachin; Paulo Nalin. Curitiba: Juruá, 2009.

FACHIN, Luiz Edson; RUZYK, Carlos Eduardo Pianovski. A dignidade da pessoa humana no direito contemporâneo: uma contribuição à crítica da raiz dogmática do neopositivismo constitucionalista. In: Revista Trimestral de Direito Civil, v. 35, jul./set. 2008. Rio de Janeiro: Padma, 2008.

G1 - Fantástico. Avô tem nome retirado de documentos da neta. Data: 15/03/2015. Disponível em: <http://g1.globo.com/fantastico/noticia/2015/03/avos-tem-nomes-retirados-de-documentos-da-neta.html>. Acesso em: 16/11/2016.

LÔBO, Paulo Luiz Netto. Entidades familiares constitucionalizadas: para além do numerus clausus. Anais do III Congresso Brasileiro de Direito de Família: Família e Cidadania, IBBDFAM/OAB-MG, Belo Horizonte, 2002.

FACHIN, Luiz EdsonDireito civil: famílias. 4ª Ed. São Paulo: Saraiva, 2011.

MADALENO, Rolf. Curso de direito de família. Rio de Janeiro: Forense, 2008.

MATOS, Ana Carla Harmatiuk. A família recomposta: em busca de seu pleno reconhecimento jurídico. In: MATOS, Ana Carla Harmatiuk; MENEZES, Joyceane Bezerra (Org.). Direito das famílias por juristas brasileiras. São Paulo: Editora Saraiva, 2013, p. 319-335.

FACHIN, Luiz EdsonPrincípio da pluralidade familiar. In: Dicionário de princípio jurídicos. Org.: Ricardo Lobo Torres; Eduardo Takemi Kataoka; Flavio Galdino. Rio de Janeiro: Elsevier, 2011.

MORAES, Maria Celina Bodin de. A nova família, de novo: Estruturas e função das famílias contemporâneas. Revista Pensar, Fortaleza, v. 18, n. 2, 2013. Disponível em: <http://ojs.unifor.br/index.php/rpen/article/view/2705>. Acesso em:07/11/2016.

OLIVEIRA, Lamartine Correa de; MUNIZ, Francisco José Ferreira. Curso de direito de família. 4. ed. Curitiba: Juruá, 2003.

OLIVEIRA, Ligia Ziggiotti de. Olhares feministas sobre o Direito das Familias contemporâneo: perspectivas críticas sobre o individual e o relacional em família. Rio de Janeiro: Lumen Juris, 2016.

PEREIRA, Rodrigo da Cunha. Princípios fundamentais norteadores para o direito de família. Belo Horizonte: Del Rey, 2005.

PEREIRA, Tânia da Silva. O "melhor interesse da criança". In: O melhor interesse da criança: um debate interdisciplinar. Coord.: Tânia da Silva Pereira. Rio de Janeiro: Renovar, 1999.

PIANOVSKI RUZYK, Carlos Eduardo. Famílias simultâneas: da unidade codificada à pluralidade constitucional. Rio de Janeiro: Renovar, 2005. 
STF. RE 898.060/SC. Rel. Min. Luiz Fux. Disponível em: <http:/ / www.stf.jus.br/portal/jurisprudenciarepercussao/verAndamentoProcesso.asp?incidente=4803092\&nu meroProcesso=898060\&classeProcesso=RE\&numeroTema=622\# $>$. Acesso em: 07/11/2016.

STEIN, Thais Silveira. O estabelecimento da paternidade e a dignidade da pessoa humana nas relações familiares. In: A ética da convivência familiar. Coord. Tânia da Silva Pereira; Rodrigo da Cunha Pereira. Rio de Janeiro: Forense, 2008.

TEPEDINO, Gustavo. Temas de Direito Civil. 3ª Ed., rev. e atual. Rio de Janeiro: Renovar, 2004.

TJPR, Vara da Infância e da Juventude de Cascavel. Processo 0038958-54.2012.8.16.0021. Julgado em: 20/02/2013. Disponível em: <http://www.flaviotartuce.adv.br/assets/uploads/jurisprudencias/201302281223270.multiparent_sentpr.PDF $>$. Acesso em 11/11/2016.

TJRJ. Ação de divórcio consensual cumulada com Declaratória de Multiparentalidade 006025843.2015.8.19.0002, Juiz Marcio Quintes Gonçalves, Julgado em 06/06/2016. Disponível em: <http://ibdfam.org.br/assets/img/upload/files/Senten\%C3\%A7a\%20Andr\%C3\%A9a\%20Cordovil\%20e\%20Si mone\%20Rabello\%20-\%20RJ.PDF>. Acesso em: 08/12/2016.

TJRJ. AI 54488-46.2013.8.19.0000, Rel. Desa. Teresa de Andrade Castro Neves, DJe 07/05/2014. Disponível em:

<http://www.direitohomoafetivo.com.br/anexos/juris/1374__b5f22016930b784eaae6086d64037ce.pdf.>. Acesso em: 16/11/2016.

TJRO, 1a Vara Cível de Ariquemes. Processo 0012530-95.2010.822.0002. Disponível em: <https://www.tjro.jus.br/appg/faces/jsp/index.jsp>. Acesso em 14/11/2016.

TJSP. AC 0006422-26.2011.8.26.0286, Rel. Des. Alcides Leopoldo e Silva Júnior, DJESP 11/10/2012. Disponível em: <http://esaj.tjsp.jus.br/cjsg/getArquivo.do?cdAcordao=6104770\&vlCaptcha=esbbm $>$. Acesso em 09/11/2016.

Trabalho enviado em 24 de maio de 2017.

Aceito em 10 de junho de 2017. 